\title{
A review: dew water collection from radiative passive collectors to recent developments of active collectors
}

\author{
B. Khalil ${ }^{1,2} \cdot$ J. Adamowski ${ }^{1}$ A. Shabbir ${ }^{1}$ C. Jang ${ }^{1} \cdot$ M. Rojas ${ }^{1} \cdot$ K. Reilly ${ }^{1}$ \\ Bogdan Ozga-Zielinski ${ }^{3}$
}

Received: 28 March 2015/Accepted: 11 November 2015/Published online: 14 December 2015

(C) Springer International Publishing Switzerland 2015

\begin{abstract}
Dew water is water droplets formed due to condensation of atmospheric water vapor on surfaces of temperature below its dew point temperature. Dew water can be seen as a nonconventional source of water and may be exploited in regions where weather conditions favor dew formation and inadequate supply and quality of water is a prevalent problem. There are two main types of dew condenser, the apparatus used to collect dew water, namely radiative (also called passive) and active condensers. Radiative passive collectors rely on exploiting the physical processes responsible for dew formation to collect dew water without any additional energy input. Previous studies indicate that a $1 \mathrm{~m}^{2}$ radiative condenser yields between 0.3 and $0.6 \mathrm{~L} /$ day of dew water in arid and semi-arid regions. Active condensers have been designed as an alternative method of collection that produces higher yields by using additional energy inputs. Several designs of active condensers have been patented for which the yield can reach $20 \mathrm{~L} /$ day for portable devices, and up to $200,000 \mathrm{~L} /$ day for larger agricultural water devices. Active condensers are also known as atmospheric water generators, dehumidifiers, and air to water devices. Most of the active condensers are based on a regenerative desiccant that attracts
\end{abstract}

B. Khalil

bahaa.e.khalil@mcgill.ca; bahaa_khalil@rocketmail.com

1 Department of Bioresource Engineering, McGill University, Macdonald Stewart Building, 21111 Lakeshore Road, Sainte-Anne-de-Bellevue, QC H9X 3V9, Canada

2 Department of Civil Engineering, Faculty of Engineering, Mataria, Helwan University, Cairo, Egypt

3 Department of Environmental Protection and Development, Faculty of Environmental Engineering, Warsaw University of Technology, Warsaw, Poland and holds large volumes of water from the air or on a means of cooling the condensing surface below the dew point temperature (refrigeration circuit). The larger yields and wider range of environmental conditions in which dew can be collected make active condensers a promising option as an alternative or supplemental source of water in water scarce regions. The aim of this paper was to provide a comprehensive review of radiative and active condensers, including dew formation processes, methods of dew collection, and parameters that influence the dew collection. Subsequently, patents of active condensers were reviewed to ascertain how they can be integrated with different types of renewable energy and to assess the potential use of such integrated systems as a sustainable source of water in regions that suffer water scarcity and/or as a sustainable source of water for agriculture.

Keywords Dew water - Atmospheric water - Radiative condensers $\cdot$ Water vapor

\section{Introduction}

Dew water collection can be considered as a non-conventional source of water which can enhance water supply in certain climates/regions. Hence, it can be considered as a possible alternative or supplementary source of water in many water scarce regions of the world where weather conditions favor dew formation. The atmospheric air can be considered as a huge renewable reservoir of water which can be used as a water source everywhere on the earth (Hamed et al. 2010). The amount of water in air is assessed as $14,000 \mathrm{~km}^{3}$, while the amount of fresh water in the earth is about $1200 \mathrm{~km}^{3}$ (Hamed et al. 2010). Despite this significant volume of potentially extractable fresh water in 
many places where weather conditions favor dew formation, dew water collection systems are rare, suggesting dew collection is an under-explored alternative for providing good quality water.

Current dew water collectors are divided into two main types: radiative (or passive) and active dew water condensers. Research on radiative condensers started in the early 1960s (Gindel 1965). Since then, research has focused on the condenser materials, architecture, influence of meteorological parameters, and other factors that affect the volume of dew water collected using radiative condensers. According to the radiative energy available for condensation, the upper limit of dew yield is $0.8 \mathrm{~L} /$ day $/ \mathrm{m}^{2}$ (Monteith and Unsworth 1990). However, the maximum recorded yields of dew water in arid and semi-arid climates typically fall within a range of $0.3-0.6 \mathrm{~L} / \mathrm{day} / \mathrm{m}^{2}$ of surface area (Muselli et al. 2009; Maestre-Valero et al. 2011; Lekouch et al. 2012). Studies conducted in more humid climates showed lower yield; for example, in a perennial grassland environment in the Netherlands, the maximum water collected was $0.19 \mathrm{~L} /$ day $/ \mathrm{m}^{2}$ (Jacobs et al. 2008); for a humid tropical island in French Polynesia, the maximum amount was $0.23 \mathrm{~L} / \mathrm{day} / \mathrm{m}^{2}$ (Clus et al. 2008); and in an agricultural environment near an urban area in SainteAnne-de-Bellevue, QC, Canada, the maximum amount was $0.37 \mathrm{~L} / \mathrm{day} / \mathrm{m}^{2}$ (Khalil et al. 2015).

Early designs for active dew condensers were developed in the 1930s, but innovation has increased since the commercialization of mechanical refrigeration (Wahlgren 2000). Active condensers are now considered an innovative option for locally managed water supply systems in areas with water quality and/or quantity problems (Wahlgren 2000). Active condensers work in a manner similar to that of a dehumidifier to extract water from the air. Although they are more effective than the radiative condensers in terms of water yield per day, they require a source of energy which makes their operating costs much higher than those of radiative condensers which do not require an energy source. However, recent active condensers are designed to minimize the energy required or make use of renewable energy resources that can be integrated into the condenser. For example, most modern solar stills integrate additional solar cells to provide supplementary energy to the system (Bundschuh and Hoinkins 2012). Active condensers are also often equipped with filtration and purification units such as ozone treatment units. The water yield of active condensers varies depending on the design/purpose; yields fall within the range of $15-50 \mathrm{~L} /$ day for a small portable drinking water unit to up to $200,000 \mathrm{~L} /$ day for larger agricultural scale designs (Peters et al. 2013). In this paper, a comprehensive review for different radiative and active condensers was provided and their potential for agricultural uses was discussed.

\section{Radiative systems}

Understanding the principles of dew formation is important for designing both effective radiative as well as active dew condensers that exploit these processes to collect dew. Dew formation is a natural occurrence where a phase transition from gaseous to liquid water occurs on an exposed surface (Beysens 1995; Agam and Berliner 2006). Dew formation is affected by several factors such as vapor pressure, air temperature, relative humidity, and wind speed. The vapor pressure is defined as the pressure exerted by the gaseous water in equilibrium with its liquid phase at a given temperature (McCabe et al. 1993). If the pressure increases, it will reach a maximum point where, passed that point, there will be a net loss of molecules from the atmosphere (i.e., condensation). This maximum pressure reached by the water vapor is called the saturation vapor pressure and is the point where the atmosphere is completely saturated with water molecules. The saturated vapor pressure is a function of the air temperature, and their relationship can be described by the following equation (Alnaser and Barakat 2000):

$e_{\mathrm{s}}=0.611 \exp \left(\frac{17.27\left(T_{\mathrm{a}}-273\right)}{T_{\mathrm{a}}-36}\right)$

where $e_{\mathrm{s}}$ is the saturated vapor pressure in $\mathrm{kPa}$ and $T_{\mathrm{a}}$ represents the ambient temperature in Kelvin.

When a constant atmospheric pressure is assumed, an increase or decrease in ambient temperature will also increase or decrease the saturated vapor pressure. If air is cooled at constant humidity to become saturated, the corresponding temperature at a given point is called the dew point temperature. If the temperature of an exposed surface is equal to or lower than the dew point temperature, condensation will occur (Agam and Berliner 2006). Moreover, if the exposed surface is maintained at a lower temperature than the air above it, according to Eq. (1), the saturated vapor pressure will be lower near that surface. This difference in vapor pressure is the gradient for mass transfer to take place since the water molecules in the atmosphere will go from high to low vapor pressure, allowing condensation to occur near the exposed surface without bringing the bulk of the air to its dew point temperature.

The dew formation rate depends on the amount of water vapor in the air; this amount is related to the absolute humidity (i.e., the amount of gaseous molecules in the air) and the difference between the dew point and ambient temperature. This notion is expressed by the relative humidity ( $\mathrm{RH})$, which is defined as the amount of water vapor in the air at a given temperature with respect to the maximum amount of water vapor that the air can hold at that same temperature. It can also be defined as the contribution made by water vapor to the total atmospheric 
pressure over the maximum pressure that the water vapor can exert at the current temperature (Alnaser and Barakat 2000):

$\mathrm{RH}=\frac{e\left(T_{\mathrm{a}}\right)}{e_{\mathrm{s}}\left(T_{\mathrm{a}}\right)} \times 100$

where $\mathrm{RH}$ is the relative humidity in $\%$ and $e$ is the vapor pressure in $\mathrm{kPa}$. Given the definition of the dew point temperature, the relative humidity can also be expressed as follows (Alnaser and Barakat 2000):

$\mathrm{RH}=\frac{e_{\mathrm{s}}\left(T_{\mathrm{d}}\right)}{e_{\mathrm{s}}\left(T_{\mathrm{a}}\right)} \times 100$

where $T_{\mathrm{d}}$ is the dew point temperature in Kelvin. The RH depends on both the difference between the dew point and the ambient temperature, and the humidity of the air (Alnaser and Barakat 2000).

Based on these principles, a radiative condenser (also called a passive dew condenser) rely on exploiting the physical processes responsible for dew formation to collect dew water without any additional energy input. The surface of radiative condensers has a high emittance in the infrared region of the spectrum that allows it to cool faster than other surfaces at night-time. Therefore, to attain the required dew point temperature and induce the collection of dew water, the environmental conditions have to be conducive to surface cooling and the exposed surface (i.e., the condenser) has to be optimized to enhance cooling.

Several parameters influence radiative dew collection (Fig. 1). The imposed parameters describe the meteorological conditions that enhance or reduce the formation of dew. They are related to the physical principles behind the technology of the radiative systems. The variable parameters are the components of the condenser that are modified to optimize the collection of dew.

\section{Weather conditions}

Dew water condensation occurs during the early morning (Jacobs et al. 1998; Kidron 2000) when the environmental conditions are favorable. It is important to consider the dependency of dew formation on weather conditions, such as sky emissivity, relative humidity, and wind speed, in the study of dew water condensation (Beysens et al. 2003, 2006; Shank 2006).

\section{Sky emissivity}

Low emissivity through the sky is known to prevent water vapor condensing, as it does not allow radiation to escape from surfaces at ground level (Gläser and Ulrich 2013); therefore, higher emissivity is ideal for condensation to occur. Dew formation is more likely to occur under clear skies. For example, studies in continental and coastal areas showed that yield was directly proportional to atmospheric transparency and sky visibility to infrared radiation (Beysens et al. 2006; Muselli et al. 2009).

Surfaces cool at night since there is a net flux of radiation energy emitted toward the sky. This radiation lies in the infrared region of the spectrum $(\lambda, 8-13 \mu \mathrm{m})$, which is the region associated with thermal radiation (Alnaser and Barakat 2000). During the night, the net radiation of a surface is emitted toward the sky and a fraction of the radiation is lost to space. However, the radiative energy can partially be absorbed by the water and carbon dioxide in the atmosphere, and part of this absorbed energy is radiated back to the surface, reducing the net long wave radiative cooling effect (Beysens et al. 2007). Therefore, clear nights when there is a lot of water held in the atmosphere are more conducive to thermal cooling of radiative surfaces than cloudy nights.
Fig. 1 Factors affecting dew collection

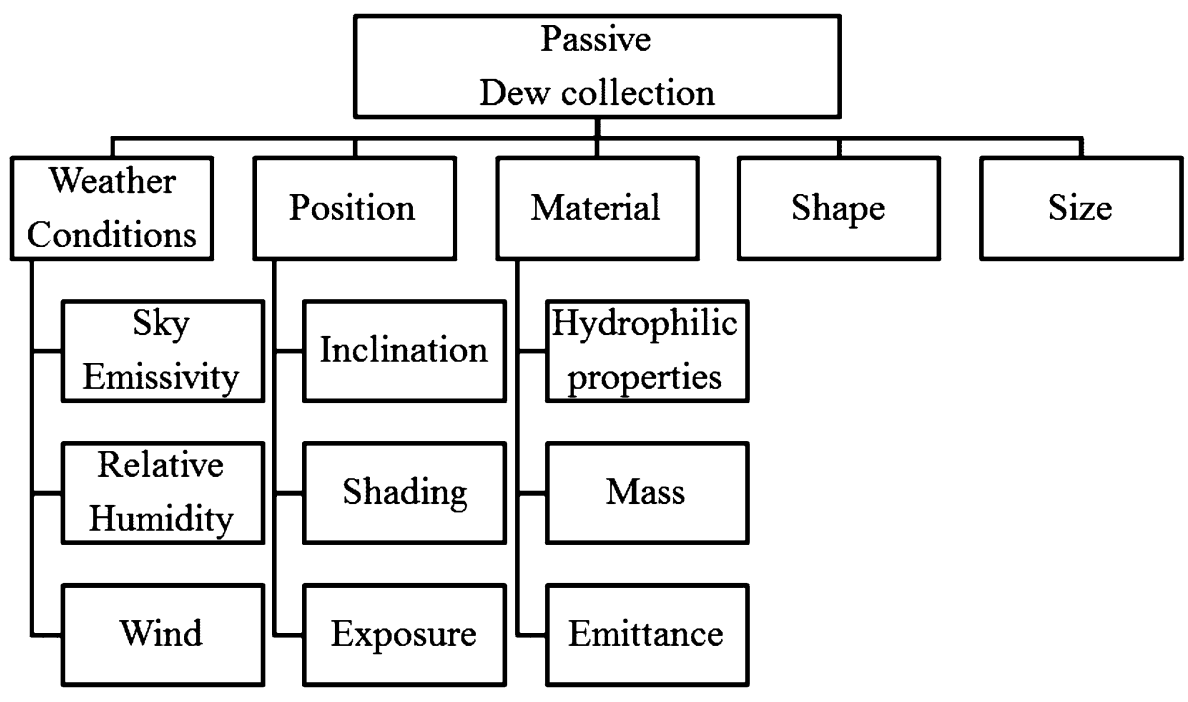


As clear nights allow greater surface cooling, they are optimum for dew formation, as opposed to cloudy nights (Kidron 2000). Muselli et al. (2009) found that dew yields decreased approximately linearly with the increase of mean cloud cover, which was used as an indicator of thermal emissivity of the sky, as described by the following equation:

$h=h_{0}(10-\bar{N})$

where $\bar{N}$ is the mean night-time cloud cover that was equal to 0 for clear sky and 10 for totally cloudy sky; $h$ is the mean dew yield (mm/day) and $h_{0}$ is the mean dew yield when the cloud cover was equal to zero. It is important to note that in this experiment the maximum yield did not correspond to $\bar{N}$ being zero but to $\bar{N}$ being approximately three. In fact, the dew yield was relatively low for the nights that were totally clear; for two sites situated in the Mediterranean basin, $h_{0}$ was equal to 0.018 and $0.016 \mathrm{~mm}$, which is relatively low when considering that the mean dew yield was 0.138 and $0.108 \mathrm{~mm}$, respectively.

The discrepancy between mean dew yield and yield when skies were clear can be explained by the fact that a clearer sky also corresponded to drier air (Muselli et al. 2009), showing that a certain level of absolute humidity is required for dew condensation to occur. For example, it has been found that the frequency at which dew events occurred in humid environments was $20 \%$ higher than in semi-arid Mediterranean climates, which resulted in a higher cumulative dew water formation during the summer in the humid environment $\left(5.58 \mathrm{~L} / \mathrm{m}^{2} /\right.$ summer $)$ than in the semi-arid environment $\left(3.5 \mathrm{~L} / \mathrm{m}^{2} /\right.$ summer) (Clus et al. 2008). In addition, a study in Morocco concluded that circulation of humid marine air was an important factor controlling dew yield (Lekouch et al. 2012), again showing the importance of atmospheric water content for dew condensation.

However, the absolute humidity of the atmosphere also affects the emissivity of the sky, with radiation being reduced when absolute humidity is high. For example, the high absolute humidity in environments such as wetland ecosystems or tropical climates hinders dew formation (Clus et al. 2008; Xu et al. 2013). Conversely, the drier Mediterranean climate allows for higher dew yields (Clus et al. 2008).

\section{Relative humidity}

The relative humidity is highly correlated to dew water yields. In a study comparing two large $\left(30 \mathrm{~m}^{2}\right.$ in area) passive dew condensers in Ajaccio, France, Muselli et al. (2006) found that the limiting value of humidity below which dew did not form was 80.7 and $79.3 \%$ for both condensers. Similarly in southwest Morocco, Lekouch et al. (2012) found that water mostly condensed when the relative humidity was between 74 and $92 \%$. In the same study, the authors defined the relationship between the relative humidity and the air and dew point temperature difference as (LeKouch et al. 2012):

$\ln (\mathrm{RH})=k\left(T_{\mathrm{a}}-T_{\mathrm{d}}\right)$

where $k$ is a constant that varied only slightly with the air temperature $T_{\mathrm{a}}$ in Kelvin. This relationship was found to be important since nearly all the data points were below the line described by the equation (Clus et al. 2008; Lekouch et al. 2012):

$h=\frac{h^{\prime}}{\Delta T_{0}}\left[\Delta T_{0}-\left(T_{\mathrm{d}}-T_{\mathrm{a}}\right)\right]$

where $h^{\prime}$ is the maximum yield for one night $\left(\mathrm{L} / \mathrm{m}^{2} /\right.$ day) and $\Delta T_{0}$ was the maximum difference in temperature between the surface of the condenser and the air (Clus et al. 2008; Lekouch et al. 2012). The $\Delta T_{0}$ can be used as a measure of the performance of the dew condenser in a specific location; for example, $\Delta T_{0}$ was used to compare the efficiency of dew collection in three locations: Morocco, Zadar and Komiza (Croatia). In Morocco it was found that the maximum temperature difference between the surface of the condenser and the air temperature was $-5.3{ }^{\circ} \mathrm{C}$, whereas the difference was slightly greater in the two locations situated in the Adriatic area of the Mediterranean basin; in Zadar it was $-9.2{ }^{\circ} \mathrm{C}$, and in Komiza it was $-8.0^{\circ} \mathrm{C}$ (Muselli et al. 2009; Lekouch et al. 2012). Thus, it can be concluded that the surface of the condenser cooled to a greater extent in the Adriatic locations than in Morocco.

The linear relationship described in Eq. (6) suggests that the difference between air and dew point temperature, or the relative humidity, can be the main parameter that limits the dew yield. In fact, several studies have found a linear relationship between the dew yield and difference between the air and dew point temperature and, therefore, a logarithmic relationship with the relative humidity (Sharan et al. 2007; Muselli et al. 2009). However, Muselli et al. (2009) did not find this linearity statistically significant. Muselli et al. (2009) concluded that the relative humidity alone was not enough to model dew yield, and that the night net radiation was another important parameter in the formation of dew on condensers.

\section{Wind speed}

Wind has both a hindering and enhancing effect on dew condensation. It is necessary to bring humid air, but also reduces radiative cooling by increasing the heat exchange between the warmer air and the surface of the collector 
(Beysens et al. 2003). Gandhidasan and Abualhamayel (2005) suggested that in dry conditions, strong winds do not favor dew condensation. In a study conducted in the humid tropical island of French Polynesia, dew yields declined rapidly for wind velocities higher than $3 \mathrm{~m} / \mathrm{s}$, and dew was almost absent for velocities higher than $4 \mathrm{~m} / \mathrm{s}$ (Clus et al. 2008). Similarly, the limiting wind speed for condensation in the Adriatic area of the Mediterranean basin was $4.7 \mathrm{~m} / \mathrm{s}$, according to a study conducted in Zadar (Muselli et al. 2009). Therefore, protecting the condenser from direct wind can be beneficial for improving dew condensation. On the other hand, low wind speeds are necessary to bring atmospheric water vapor to the surface of the condenser; a study in southwest Morocco found that dew formed when wind was in the range of $0.15-0.7 \mathrm{~m} / \mathrm{s}$ (Lekouch et al. 2012).

The technology behind radiative dew water collection system is relatively simple as it relies on exploiting the physical processes of dew formation, and no additional energy input is necessary. However, the radiative cooling power of passive dew collectors is a function of the weather (ambient temperature, relative humidity, and cloud cover), which affects yield in relatively complex ways. Overall, however, the ideal weather conditions are usually found in arid and semi-arid climates, which also tend to be water scarce. By implementing this technology, it will be possible to produce drinkable water with no additional energy input and consequently with a very small footprint. However, due to the very particular weather conditions necessary for maximum condensation of dew (i.e., relative humidity $\sim 80 \%$, and cloud cover and wind speed low but greater than zero), the water yield per day is typically relatively low and difficult to predict. This makes dew collection using radiative condensers a non-reliable water source, although optimizing condenser design can go some way to improving yields.

\section{Design of radiative dew condensers}

Given the dependence of radiative systems on the dew formation physical processes, their design has to be optimized to allow surface cooling without any external energy input. In particular, there are a number of factors that must be optimized to increase the yield. First, it is important to maximize the infrared wavelength emitting properties of the condensing surface to allow surface cooling at night. Second, absorption of the visible light must be reduced to prevent daytime warming of the condenser, which means having a higher reflectivity in the visible part of the spectrum (i.e., white materials). Third, the heating effect of the wind must be reduced by lowering its velocity, which is usually achieved by having a tilt angle on the condenser or a specific shape. Fourth, a hydrophilic surface is needed to recover most of the water, so it can be collected in a container, and to avoid evaporation of the water in the early morning. Finally, it is important to have a light condenser to reduce heat inertia, making it easier to change the temperature of the surface, and to have good insulation to avoid heat transfer from the ground (Beysens et al. 2006, 2007; Clus et al. 2009). This said, it is possible to divide the optimization factors of the design and location of radiative systems into the material, shape, and size of the collector, and its position.

\section{Surface material}

Dew formation is influenced by the properties of the material used for the surface of the condenser. By selecting the appropriate material, the energy barrier at the liquidvapor interface can be lowered to enhance water recovery. Alnaser and Barakat (2000) tested three different types of materials and the results showed that aluminum had the highest potential use as a dew water collecting surface, followed by glass and polyethylene. They came to the conclusion that a polished surface enhances dew collection by letting the water easily run along the surface. Kidron (2010) found that a smooth Plexiglas surface collected 0.21 $\mathrm{L} / \mathrm{m}^{2} /$ day of dew water, compared to a rough surface that collected $0.1 \mathrm{~L} / \mathrm{m}^{2} /$ day.

Another property that affects dew condensation is the mass of the material, which affects the ability of the condenser to lower its temperature, since condensers with a higher mass have higher thermal inertia. For this reason, insulation beneath the condenser is necessary to prevent heat transfer between the soil (or the condenser frame) and the surface sheet of the dew condenser (Beysens 1995; Nikolayev et al. 1996). For example, a study in North West India of plain, uninsulated corrugated galvanized iron roofs measured a maximum cooling temperature of $2{ }^{\circ} \mathrm{C}$, while a condenser that was thermally insulated using a foil with a higher emissivity had a maximum cooling of around 3.4-3. ${ }^{\circ} \mathrm{C}$.

In addition to being light, having high wetting properties, and being thermally insulated from the ground, the condenser material needs to have a high emittance in the infrared region of the spectrum to enhance its cooling properties (Alnaser and Barakat 2000). The standard foil recommended by the International Organization for Dew Utilization (OPUR) is a white hydrophilic foil of titanium dioxide and barium sulfate microspheres embedded in polyethylene. The OPUR standard foil is said to improve emitting properties in the near infrared region by providing radiative cooling at normal ambient temperatures. At the same time, it reflects visible light, thus increasing the time for dew collection in the early morning. Maestre-Valero et al. (2011) compared the standard white hydrophilic foil 
recommended by the OPUR (yield 17.36 L) with a lowcost black polyethylene foil (BF) used for mulching in horticulture (yield 20.76 L). The OPUR foil and BF foil had the same emissivity in the wavelength of 7-14 $\mu \mathrm{m}$ $(\varepsilon=0.976)$. However, the BF had a higher emissivity in the wavelength of 2.5-7 $\mu \mathrm{m}$ (BF: 0.996; OPUR foil: 0.833) and 14-25 $\mu \mathrm{m}$ (BF: 0.998; OPUR foil: 0.990). The better performance of the BF showed that the increase of emissivity in the infrared spectrum resulted in a higher yield than an increase in the surface hydrophilic properties. This indicates the importance of the emittance of the material, with high emittance being needed not only in the near infrared spectrum but also in the entire mid-infrared spectrum (Maestre-Valero et al. 2012).

\section{Shape}

The shape of the dew water collector and its influence on water yield has been studied in terms of simple hollow structures and non-plane sheets. Dew collection from hollow funnel-like structures showed an increase in the collector efficiency compared to a $1 \mathrm{~m}^{2}$ standard planar collector. This standard collector is a polyethylene sheet embedded with microspheres of titanium dioxide and barium sulfate tilted at a $30^{\circ}$ angle to the horizontal. Beysens et al. (2012) hypothesized that hollow forms reduced the heat exchange between the air and the condenser surface by reducing free convection; it was found that a cone halfangle of $30^{\circ}$ gave the best results among all the tested inclinations $\left(25^{\circ}, 30^{\circ}, 35^{\circ}, 40^{\circ}\right.$, and $\left.50^{\circ}\right)$. In a grassland area in the Netherlands, an inverted pyramid with an angle of $30^{\circ}$ collected $20 \%$ more water than a standard $1 \mathrm{~m}^{2}$ planar dew collector (Jacobs et al. 2008). Similarly, a simulation done under typical meteorological conditions (i.e., clear sky, ambient temperature of $15{ }^{\circ} \mathrm{C}$ and relative humidity of $85 \%$ ) showed that a funnel shaped condenser with a half-angle of $30^{\circ}$ had a higher performance by $40 \%$ compared to the reference plate. The funnel shape was found to reduce the flow of warm air and block the heavier cold air at the bottom, thus avoiding natural convention (Clus et al. 2009).

Concerning non-planar collectors, three shapes of sheet with different relief have been tested: egg-box, origami and multi-ridge. The origami structure compared to the egg-box structure showed better performance because the egg-box structure hindered the flow of dew water due to its flat top (Beysens et al. 2012). The multi-ridge condenser did not show any difference in performance compare to a flat reference condenser, but when the wind speed increased above $1.5 \mathrm{~m} / \mathrm{s}$, the multi-ridge condenser showed an increase in efficiency of $40 \%$ (Clus et al. 2009).
Size

The size of the condenser has been found to influence its performance. For example, an on-ground $900 \mathrm{~m}^{2}$ condenser showed a decrease in yield of $42 \%$ compared to four $1 \mathrm{~m}^{2}$ standard condensers. It was suggested that the large size of the condenser allowed the foil to fold, which increased water stagnation, thus affecting the radiative cooling effect (Sharan et al. 2007). However, Kidron (2010) found that a decrease in size from a 0.16 to a $0.01 \mathrm{~m}^{2}$ condenser reduced the yield from 0.25 to $0.15 \mathrm{~L}$. The reduction in size on both axes (e.g., from $10 \mathrm{~cm}$ by $10 \mathrm{~cm}$ to $5 \mathrm{~cm}$ by $5 \mathrm{~cm}$ ) showed a greater decrease in yield than when one axis was kept constant (e.g., from $20 \mathrm{~cm}$ by $10 \mathrm{~cm}$ to $10 \mathrm{~cm}$ by $10 \mathrm{~cm}$ ). This suggests that there is a border effect that reduces the efficiency of the condenser surface toward the edges. This issue has not yet been explored in detail.

\section{Position}

The position of the dew condenser, in terms of its inclination, shading and exposure, influences the condensation of water. First, it was found that an angle of $30^{\circ}$ with respect to the horizon was the optimal inclination to minimize the heat exchange effect caused by wind, increase the water recovery by gravitational force and not hinder the visibility to the sky that is needed for radiation cooling. For example, a study in Grenoble, France, found that when the condenser was inclined at an angle of $30^{\circ}$, the yield of dew water increased by up to $20 \%$ when compared to a nearby horizontal reference plate (Beysens et al. 2003).

Second, studies of dew condensation showed different results for condensers in the sunlight and in the shade. For example, an experiment in Israel showed higher yields in the shaded areas (Kidron 2000). Furthermore, in north-west India, water condensation was $35 \%$ higher for a condenser that remained longer in the shade than for one exposed to sunlight (Sharan et al. 2007).

Finally, studies showed that exposure to the sky also affected condensation rates by being related to radiative cooling. A site surrounded by high altitude topography will have the infrared radiation that the condenser emits reflected back by the hills or mountains (Beysens et al. 2007). For example, a study comparing an uphill site with a downhill site showed that the yield from the latter was $40 \%$ lower than that of the uphill site (Kidron 2000). In addition, Muselli et al. (2006) showed that a condenser exposed from the sides had a higher yield (mean dew yield: $0.118 \mathrm{~L} /$ day) than one that was enclosed and closer to the ground (mean dew yield: $0.111 \mathrm{~L} /$ day). 
The optimization of radiative condensers allows yield to be increased by changing the design of the condenser from a flat plate to more complex shapes and materials. First, an optimal inclination of $30^{\circ}$ decreases the heating effect of wind on the condenser (force convection) and enhances water collection by gravity. In addition, an inverted hollow structure such as a cone or pyramid reduces the negative consequences of convection even further, including free convection. However, producing a hollow structure is more complicated than producing plane condensers. Second, the emittance properties of the material can significantly enhance dew condensation. The standard OPUR sheet has been shown to increase the cooling of the condensing surfaces; however, since the sheet is specially manufactured for research purposes, the cost is quite elevated. Maestre-Valero et al. (2011) studied a low-cost polyethylene foil that is commonly used in agriculture, which produced better results than the OPUR sheet. This suggests that there is further potential to lower the price of the material used as a surface collector while increasing the efficiency of the collector. Finally, the scaling up of the condenser from the $1 \mathrm{~m}^{2}$ standard has shown a decrease in efficiency of about $40 \%$ (Sharan et al. 2007), which does not allow for the collection of high volumes of dew water.

\section{Active condensers}

Given the low yields of radiative condensers and the specific environmental conditions required for dew formation, active condensers may be a viable alternative. Although relative humidity is a significant factor in the efficiency of active condensers (Peters et al. 2013), active condensers are less affected by variation in conditions such as sky emissivity, wind speed, and topographic cover than radiative condensers. Thus, they can potentially be operational under a wider range of weather conditions (Peters et al. 2013).

Active condensers can be classified into personal scale devices that can generate 15-50 L of water per day, or larger industrial scale machines, which can produce up to 200,000 L/day (Peters et al. 2013; Khalil et al. 2014). The yield of active condensers is much higher than of radiative condensers, but active condensers typically have a high energy demand. Despite this drawback, active condensers can be useful as a supplementary water source in circumstances where water supply from other sources is limited, such as an alternative source of potable water.

Active dew condensers typically use cooling condensation or regenerative desiccation to bring trapped air to the dew point temperature, thus causing the water vapor to condense for collection. Early active condenser technology used simple designs to maintain collection surfaces at cool temperatures for a longer period of time than can be achieved in radiative condensers. Subsequent technological development focused on using regenerative desiccants, which are subdivided into solar regeneration, heat exchanger coupled, and dual air pathways, and cooling condensation technology, which is further divided into ground-coupled, portable, vehicle compatible and seawater cooling. Each of these design types has benefits and drawbacks, as discussed below.

\section{Regenerative desiccant materials}

Regenerative desiccant technologies use hygroscopic materials (substances that can attract and hold water molecules through adsorption or absorption) to increase the volume of dew collected. Silica gel and zeolite are commonly used in active condensers. The capacity of hygroscopic materials to hold amounts of water greater than their own mass theoretically makes the active condensers more effective at extracting and retaining water than radiative condensers. Furthermore, low dew points can be achieved without potential freezing at moderately low operation costs. However, initial costs of desiccant materials are high and the desiccant beds must be replaced periodically. Regenerative desiccant condensers typically include a bed of hygroscopic material that can be exposed to humid air, and a stimulus source, such as solar power or heat exchangers, to extract the water content for collection in built-in or external reservoirs. It should be emphasized that some apparatuses (e.g., solar regeneration) depend on solar radiation for heating the desiccant and do not require an additional source of energy. These apparatuses cannot be considered as active condensers, but were included in this section as one of the types of regenerative desiccant condensers.

\section{Solar regeneration}

Initial designs of this type consisted of a solid or liquid desiccant that absorbed water vapor from moist air, which was subsequently recovered by heating the desiccant and condensing the evaporated water (Hamed et al. 2010). For example, an apparatus that used a high surface area of wood exposed to the nighttime air absorbed moisture of up to $30 \%$ of the dry wood's weight. During the daytime, the wood was stored in an area with large windows and glass ceilings to allow the sun's heat to evaporate the moisture from the wood. The air was then expelled to an area in the shade where the moisture condensed and was collected in a reservoir. The air was recirculated back to the wood to carry more moisture and flow back to repeat the cycle (Altenkrich 1938). Several setups used different desiccants, such as saw wood (Altenkrich 1938), silica gel (Dunkak 
1949; Ackerman 1968; Hamed et al. 2011), and recycled newspapers (Krumsvik 1998). For instance, a glass pyramid shape apparatus with a multi-shelf solar system to extract water from humid air was explored by Kabeel (2007). Saw wood and cloth were examined as beds and were saturated with $30 \%$ concentrated calcium chloride solution. During the night, the pyramid glass sides were opened to allow the desiccant to absorb moist air and during the day, the glass sides were closed to extract the moisture from the bed by solar radiation. Water evaporates and condenses on the top of the pyramid and is collected through a middle cone and through the glass inclined sides to an external reservoir (Fig. 2). The pyramid shape with multi-shelves doubled the amount of collected water compared with a solar desiccant/collector system with horizontal and corrugated beds.

Similar setups have used silica gel contained within a breather, which is a vented housing that allows air exchange with the atmosphere due to temperature and pressure differences between the two. The breather housing was coated with a dull, dark finish to allow for maximum heat absorption during the day. The heated silica gel inside was then activated, which allowed release of the water content, creating warm moist air that flowed out of the breather and condensed. The gel sat on a slotted bed, which was sufficient to allow it to collect moisture during the night-time (Dunkak 1949). Similar mechanisms can be found in different designs, such as several cone shaped thin sheets of metal stacked vertically with a desiccant in the middle. During the night, the ends of the metal sheets were raised so that the desiccant was exposed to the cool, moist air, and condensed during the day (Ackerman 1968). Recycled newspapers have also been used as desiccants housed in glass pyramid chambers (Krumsvik 1998).

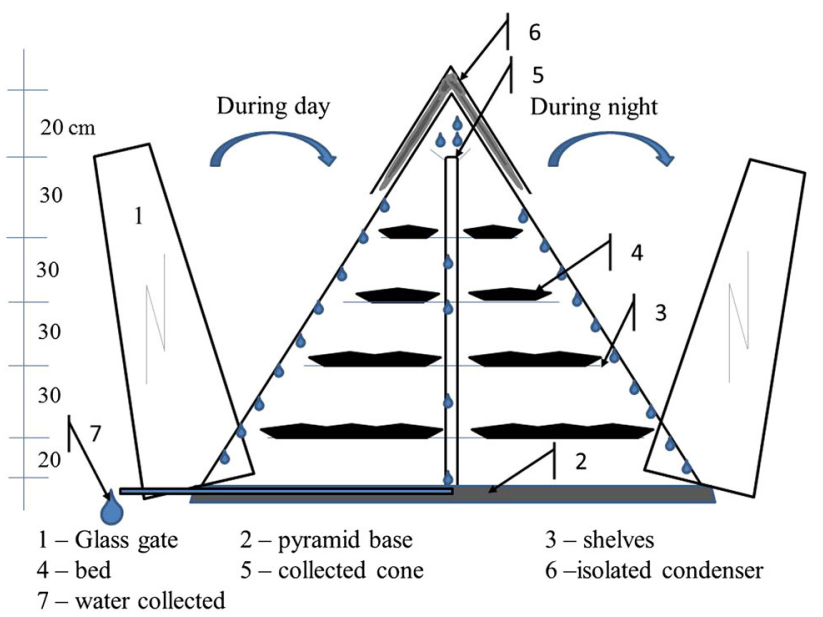

Fig. 2 Glass pyramid with shelves (open during night and closed during day)
Collectors with regenerative desiccant materials have been designed for use in a wide range of environments, and have been optimized by altering the desiccant used and the design of the collector. For example, for humid tropical regions with large temperature differences, Groth and Hussmann (1979) described a device comprising a glass sun-ray collecting top layer, followed by a coarse, granular silica gel absorbent layer, followed by a layer of non-absorbent materials, such as stones, that was stacked 3-5 m high (Fig. 3). At the bottom, fans supplied and withdrew air. This device could be $100-200 \mathrm{~m}$ in width and up to $15 \mathrm{~m}$ in length. Cool, moist nighttime air was channeled from the bottom up so that it passed the non-absorbent layer and cooled before reaching the absorbent layer, where water adsorbed to the silica. During the day, hot air flowed in the reverse order and reverse direction. The moisture desorbed from the silica gel flowed downwards into the stones (heat exchange layer) and condensed on contact with the cool surface, then flowed into a reservoir. The air flow in this phase could also be aided by a radiator (Groth and Hussmann 1979). This structure could collect 10-15 L of water per square meter of adsorbing surface over $24 \mathrm{~h}$.

For application on a larger scale in desert regions, Klemic (2005) detailed an apparatus containing a frame 1-6 m high, which held a net of superabsorbent polymer, preferably of a grain size of 50-1000 microns. This polymer was capable of absorbing moisture of several times its own weight, which was released with the application of solar power. The condensate water was collected in a trough located directly below the net. This device can be used for fog clearance and odor removal in addition to water generation, and the frame can be built from local, widely available materials.

\section{Heat exchanger coupled desiccants}

Regenerating desiccant beds with heat exchangers removed the time constraints associated with solar power and led to more control over the amount of energy supplied to regenerate the desiccants. For example, Michel and Bulang (1981) described an apparatus containing a sun collector, an adsorbent layer with a desiccant bed, and an air baffle, followed by a condenser (Fig. 4). A grated collection reservoir was located below the condenser, as well as fans below the sun collector to channel air through. Air intake was in the air baffle zone, which was open during the night to contain air inside. Upon entry, the air flow was split into two, with one partial air stream being channeled through the condenser and heat storage reservoir to cool it. The second stream is directed into the adsorbent layer, where its moisture was adsorbed. The two streams connected before exiting through the air outlet port. In the daytime phase, the water was desorbed and condensed. The air flaps were 
Fig. 3 A simplified illustration of the device proposed by Groth and Hussmann (1979)
Fig. 4 A visual representation the aforementioned apparatus described by Michel and Bulang (1981). Air stream represents the first air stream that is directed through the condenser and heat storage reservoir and Air stream 2 represents the partial air stream that is directed through the absorbent material

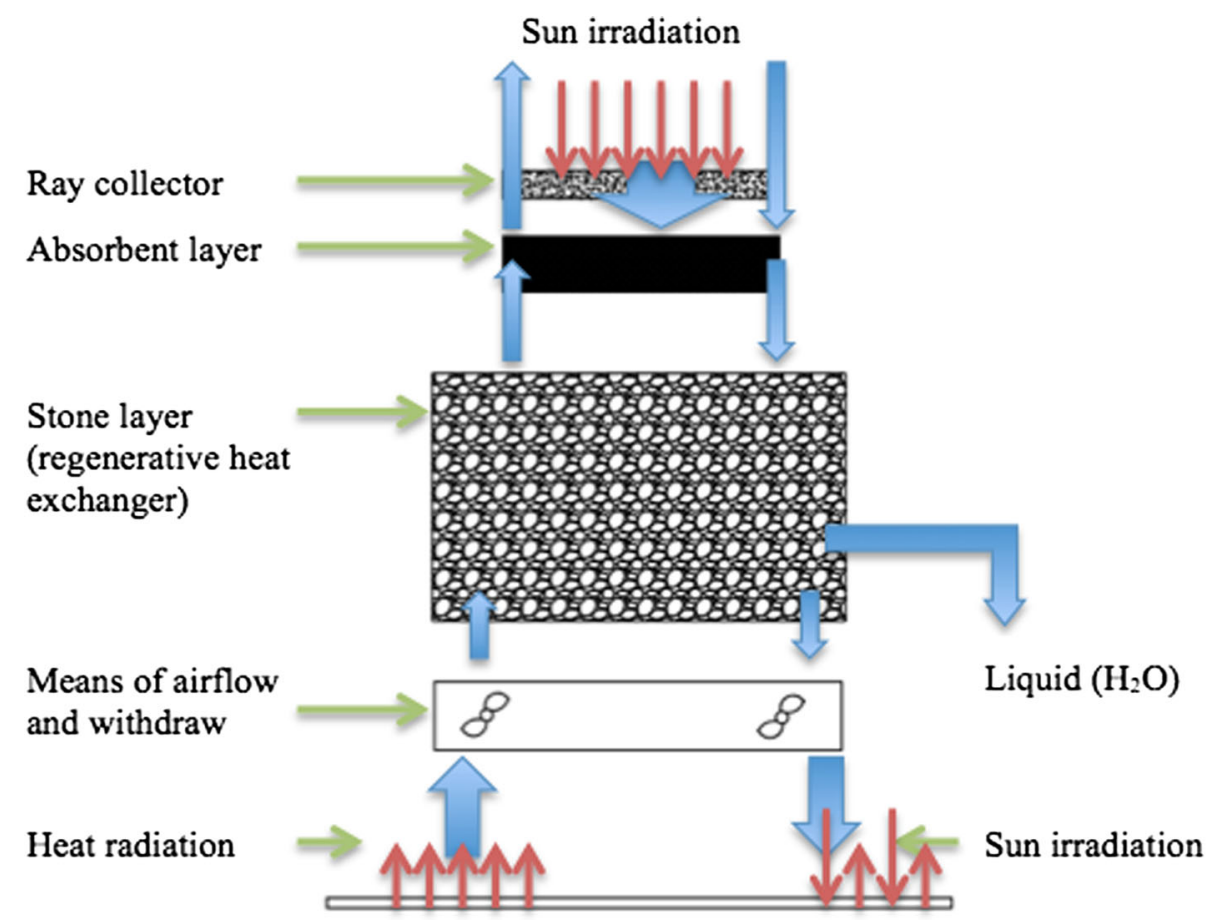

closed and mirrors concentrated sun rays to heat the air inside. Heating the adsorbent released moisture to two streams of air. One went down to the condenser layer and relinquished some of the moisture, which condensed as water droplets and was heated in the process. The warm air was recycled back through the adsorbent layer and continued to pick up more moisture. Ito et al. (1981) described similar designs with multiple desiccant beds. 


\section{Dual air paths and chambers}

Newer designs with regenerative desiccants used multiple pathways and chambers, the purpose of which was to maximize moisture extraction and increase the efficiency of batch processing. Such designs included portable sized devices that could be coupled to mobile energy sources, such as automobiles. For example, Tongue's (2007) desiccant wheel required a heat source such as that from a vehicle exhaust to provide heat to an air loop, where a heat exchanger heated the air within the loop. On one side of the loop was dry air and on the other was the humid air passage. The moist air in the second passage flowed to a condenser, from where the subsequent condensate dripped through a pipe to a reservoir, where it was filtered further before being dispensed (Call et al. 2009). An air blower channeled ambient air into a desiccant bed, the air from which was then released via heat from an energy conversion device. With the addition of heat, the high temperature, high humidity air was desorbed, passed over a condenser and collected as water droplets. The energy conversion device can be excess heat from a vehicle's motor.

Rodriguez and Khanji (2012) described another dual chambered device that incorporated a water treatment step. The closed chamber received air funneled in through fans, which was then heated to $75-82{ }^{\circ} \mathrm{C}$ and exposed to a desiccant that had been pre-absorbed with moisture from the ambient air. The hot air was humidified and then passed over condenser coils, which collected water condensate that dripped into a collection tank. The computer control extra heated the desiccant once per day to decontaminate it, and ambient air from the open air chamber was infused within it to supply the moisture. The collected water was exposed to UV light and then pumped through filters containing carbon and zinc or silver activated zeolite, before being collected in a final reservoir that rested on Peltier plates to allow the water to cool before dispensing. Water sensors could shut off or shift the output of processed water when the reservoirs were full. Ellsworth (2013) described a desiccant that included porous support material and hydroscopic absorbent dispersed within the support material. Materials such as PVA foam with calcium chloride as a chemical desiccant resulted in increased moisture adsorbing properties.

\section{Cooling condensation systems}

The second common class of active condensers contain the components of a refrigeration system to provide a cooled surface for condensation to occur, such as in a reverse cycle air conditioner (Graham and Dybvig 1946). These devices often contain a compressor, condenser, and evaporator connected by conduits that carry a refrigerant. These, in addition to pressure valves, air inlets and outlets, and water reservoirs, are generally housed in a rectangular container. The advantages offered by this approach include low initial costs, and low operating and maintenance costs. In addition, the refrigeration mechanism allows for dew collection even at times when the ambient temperature is greater than the dew point temperature, potentially making them more efficient than radiative condensers. The disadvantages include potential icing of evaporator coils and low cost-effectiveness during periods of low air flow. However, these problems have been addressed in newer models by insulation and programmable cycling compressors, respectively.

\section{Designs using cooling liquids}

Coanda and Coanda (1956) described a housing with orientable entry and exit points for wind, located near large water bodies, where warm, moist air is prevalent. Inside the housing was the first cooling radiator coil, which was connected via conduits to a second coil located beneath the soil surface that was in contact with cooler temperatures. A cooling liquid was driven through the coils by a windmill. The warm air entering the housing was cooled as it flowed through the coils, such that condensed water droplets flowed down the coils and were piped via conduits into a dispensing reservoir.

Portable atmospheric water generators also use cooling liquids to acquire potable water from ambient air of varying temperature and humidity conditions, and typically generate between 20 and $50 \mathrm{~L}$ of water per day. They also contain built-in filtration systems that remove the need for separate water treatment, making them an asset to regions without such infrastructure. Air is funneled into the device via fans through an air filter that screens out debris. Inlet air passes through evaporator and condenser coils aided by a compressor to remove the water vapor by condensation from the air. Evaporators induce liquid refrigerant vaporization, allowing the air to cool the air and the water to condense into a reservoir for collection. A compressor and condenser allow the refrigerant to return to its liquid state. The condensate is collected on a collecting pan and channeled into a reservoir where UV light is applied to kill $99.9 \%$ of microorganisms (Reidy 1992a, b). Once sufficient water has collected, it is passed through a water filter into a second reservoir where secondary UV light exposure is applied. Processing is halted if either of the UV lights malfunction or when filters require replacement or cleaning, as detected by an air pressure sensor. Sensors detect and stop water output once the external or internal containers are full and the flow of water can be shifted to secondary containers (Reidy 1992a, b). 
A programmable microchip set can be used to operate the generator. In addition to being programmed to display alerts during compromised operations, such as when the air filters need replacing, the microchip can be coupled to a thermostat and humidistat. These can be programmed to process air of a given temperature and humidity level so as to maximize the water yield for a given amount of energy needed to operate the generator. For example, at $24{ }^{\circ} \mathrm{C}$ and $50 \%$ relative humidity, up to a $3.79 \mathrm{~L}$ of water can be produced within $12 \mathrm{~min}$ (Reidy 1993). Similar designs incorporate ionic air filters and activated charcoal water filters to remove volatile organic compounds, and heat strips to prevent freezing of water when atmospheric temperatures drop below $0{ }^{\circ} \mathrm{C}$ (LeBleu 1997, 1998).

Subsequent designs allowed the collected water to be cooled or heated, as well as to be recirculated to prevent stagnation. Insulation and heating measures were also added to prevent rusting and icing of the condensing coils (e.g., Zakryk 2000; Lloyd and Baier 2002). Design modifications to prevent stagnation included a spinning reservoir that was cylindrical at the top and conical at the bottom; the vortex created by the spinning water prevented stagnation and accumulation of sediment. Additional forms of filtration included melamine deep filters and charcoal black filters. The water was chilled or heated and pumped to be dispensed from a spout located at the top (Dagan 2003). Water dispensing can be either gravity assisted or accomplished through the use of small pumps (Faqih 2004). Versatile designs can be a standalone indoor or outdoor unit, wall-mounted, mobile or attached to a vehicle (Engel and Clasby 2004; Foss 1973).

\section{Ground-coupled heat exchangers}

The ground can also be used as a heat sink to naturally induce condensation. However, one disadvantage of this approach is that underground tubes are susceptible to contamination and are difficult to clean. Courneya (1982) described an apparatus that contained a cold heat exchanger buried beneath the surface of soil or a body of water that was at or near subsurface temperature. An above ground, water collecting funnel channeled air into the system, through the heat exchanger, out through the outlet valve, and into a reservoir that collected the condensate. The outlet valve could be regulated to increase residence time of the air inside the heat exchanger to allow for sufficient condensate to form. O'Hare (1984) described a simpler apparatus that operated by the same principle with solely a blackbody pipe that extended beneath the surface (Fig. 5). In addition, Smith (1984) described a housing with a turbine and evaporator conduit. The turbine was connected to an electrical generator that powered the refrigeration system. The unit was mounted on a tower

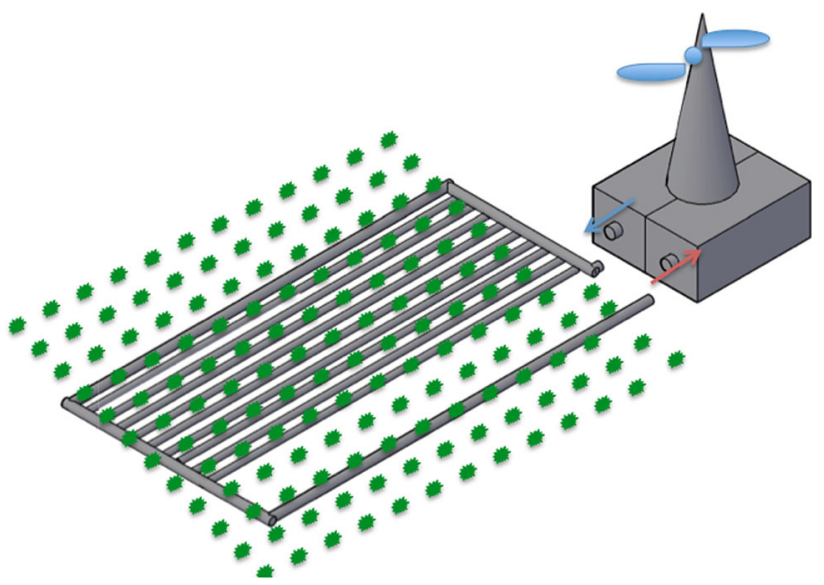

Fig. 5 An illustration of O'Hare's (1984) ground-coupled heat exchanger apparatus with the rotatable turbine tower introduced by Smith

such that it automatically rotated to point toward the wind. The cooling of the evaporator caused the air to sink and leave the unit at a lower position to where it entered, leading to denser air. A similar design contained a chamber located $6^{\prime}$ below the surface, which contained fans that helped circulate air within several conduits. When air temperature is higher or lower than ground temperature, a gradient is established and water is trapped and condensed (Rogers and Midgett 1980).

\section{Seawater cooling}

Craven's (2008) invention generated fresh water from deep cold ocean water at altitudes above sea level (Fig. 6). It included a first stage with a siphon, collecting tank and supporting structure. The irrigation piping in the siphon transported the deep ocean water high up the insulated irrigation pipe condenser, which retained the coolness of the water, and allowed the air outside to condense onto it. The layered irrigation pipes were made of materials with properties that allow them to function as a heat exchanger.

\section{Cooling using dual airflows}

Bulang (1980) described a device that took moist nighttime air and divided it into two partial air flows. The first partial air flow passed through a water-absorbing material, such as silica gel. $75 \mathrm{~g}$ of water could be absorbed for $100 \mathrm{~g}$ of the silica gel. The second partial gas flow passed through a heat accumulator where heat was transferred to it. The accumulator was deheated and the second partial gas flow was discharged. In the second stage during the daytime, a flow of moist gas that had been heated by a solar-energy collector was passed through the moisture laden water absorber from step 1 . This gas flow absorbed the moisture 
Fig. 6 Craven's seawater cooling system (Craven 2008). The top figure represents an aerial view, while the bottom figure illustrates a profile view of the system

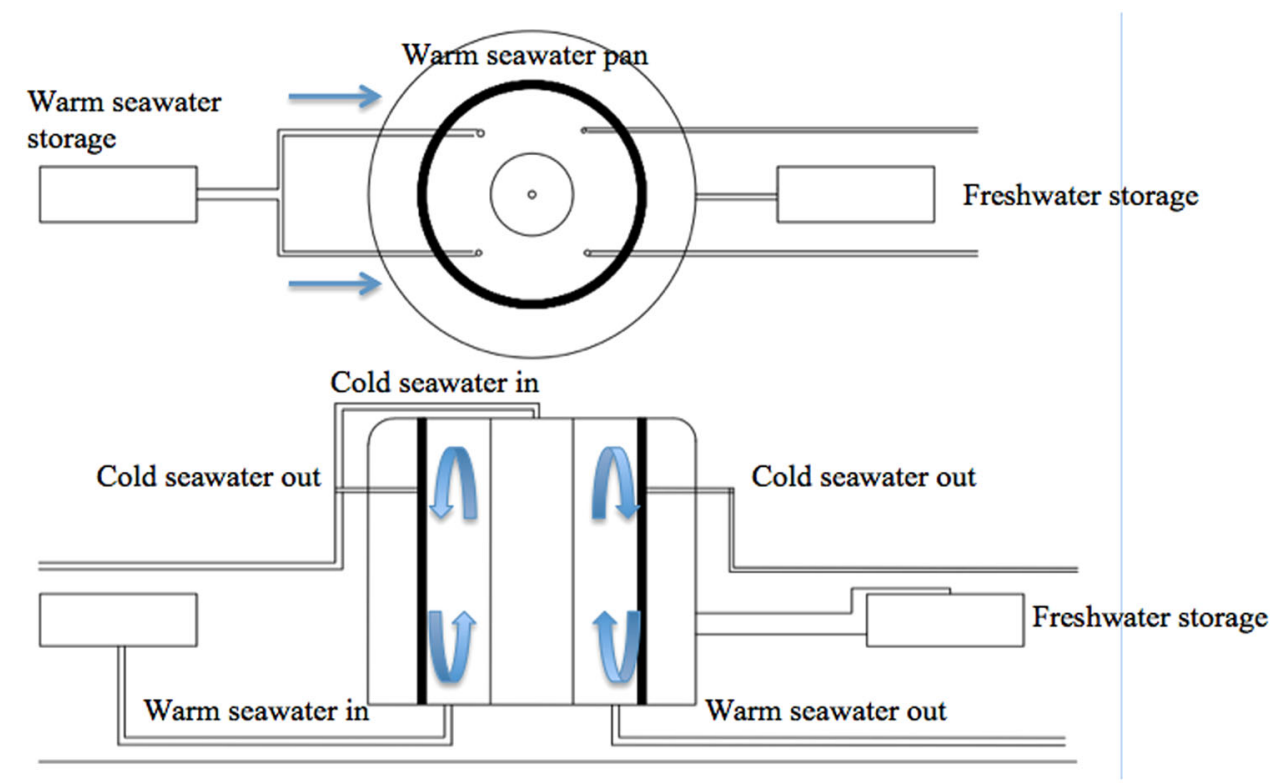

from the absorber, creating a second warmer and more humid gas flow. This gas was passed over the deheated heat accumulator, where heat was transferred to the accumulator and moisture condensed on its surface. The flow of gas was discharged and the condensate was collected. Hussmann's (1982a, b) similar device used four stages. In the first stage cool humid atmospheric air was used to cool the first heat condenser and moisten an adsorbent medium. In the second stage, warm solar heated air was used to expel moisture from the adsorbent and carry the moisture into the first heat storage condenser, where the moisture condensed and released its heat. In the third stage, a second stream of cool humid air was used to cool the second heat condenser and moisten the first adsorbent. In the fourth phase, a second stream of warm solar heated air was used to harness moisture from the adsorbent and condense it over the second heat storage condenser. The stream of air in the second phase was preheated by the second heat storage condenser from the fourth phase. The stream of hot air in the fourth phase was preheated by the first heat storage condenser, in addition to solar radiation, and this heat was also used to expel all moisture from the adsorbent.

\section{Other methods}

Ockert (1978) proposed the 'Tornook' device, which was a tall stack with an extended base (Fig. 7). Air intake was through the base, which contained inlets that imparted a rotational velocity to the air. The resulting air had a reduced pressure and the density difference aided in continuing the flow. This also led to rapid moisture loss from the air, which was precipitated due to the centrifugal force in the vortex. The remaining air was heated to be released

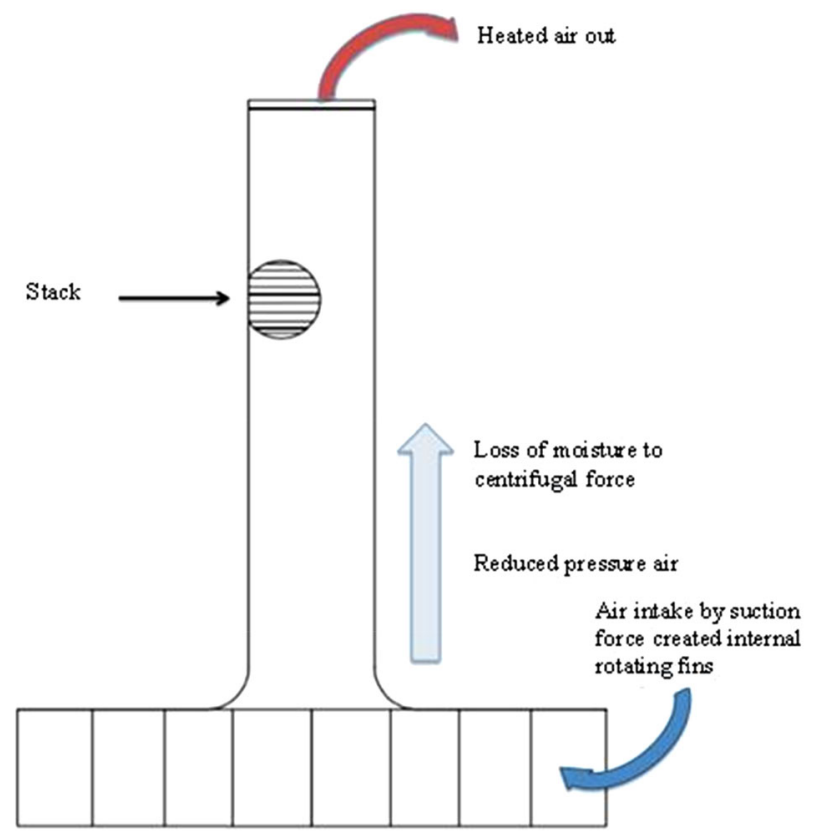

Fig. 7 A conceptual profile view of the Tornook device Ockert (1978)

from the top of the stack, and the resulting pressure differential allowed for new air to enter from the base. High humidity resulted in a stronger vortex.

Peltier systems, which consist of a unit that transfers heat from one side to the other powered by electricity, have been used to provide water directly to plants for irrigation. Biancardi (1982) described a Peltier system that contained a housing, a condensation member and a pair of electrical 


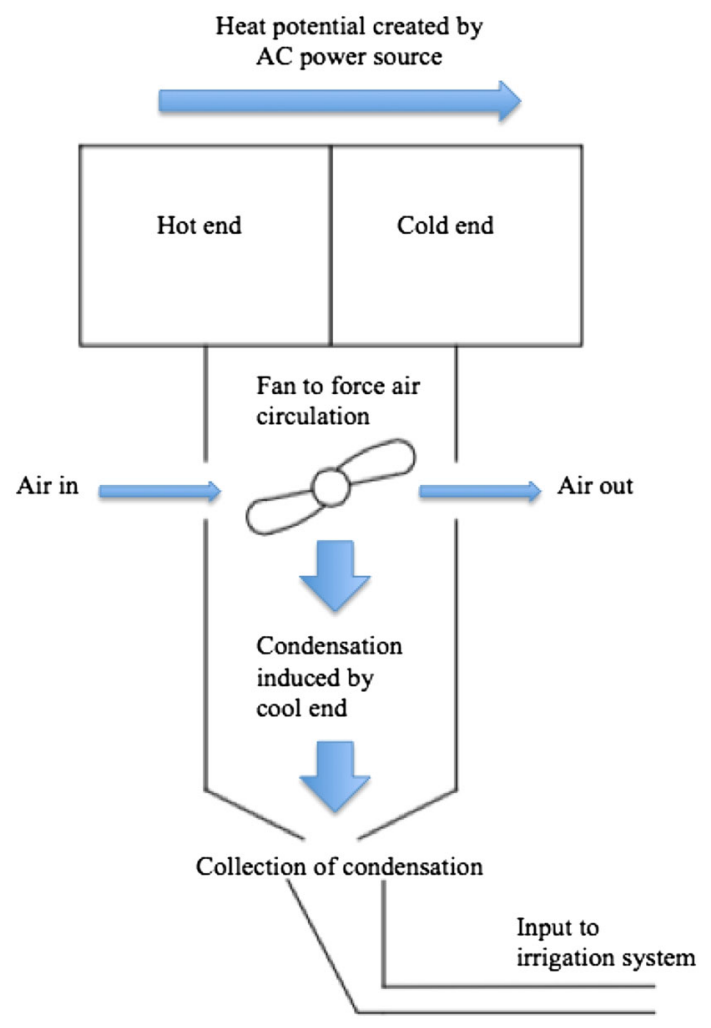

Fig. 8 Conceptual representation of Tircot's Peltier system

probes. The probes were stuck in the soil such that the condensation member resided above the soil. In addition, a thermocouple such as a Peltier crystal, which contains a hot and cold side when electricity is conducted, was included. The hot side contained a heat sink and the cold side contained a conductor that removed heat from the conduction member, making it cooler. The cooled conduction member allowed condensation of moisture from the atmosphere; this condensation was then channeled into a small collection reservoir and subsequently into the soil (Muñoz-García et al. 2013). The electricity source for the system could be a battery or an AC current source. Similarly, Tircot's (1985) apparatus utilized the Peltier effect and had a hot end that was in contact with a heat dissipater and a cold end in contact with a thermally insulated condenser powered by an AC current (Fig. 8). Air entered the chamber and induced the condensation of water into droplets that were collected in an external reservoir. A fan and thermometer can also be used to force air and detect temperatures inside the chamber to ensure adequate processing.

\section{Large-scale designs}

Faqih (2005) offered several prototypes for collecting water for human, animal and irrigation purposes using flat, vertical or conical condensation surfaces. Evaporator coils were installed behind the condenser surfaces, where humid air lost moisture on contact with the surface; the condensation collected on these surfaces dripped down into a collection pan. The water could then be filtered and appropriated for use. These devices used thermo-acoustic engines, which use high intensity sound waves to generate superhot gas molecules that transfer their energy to coils and then expand and cool, rather than standard refrigeration systems.

\section{Implications for optimization and use of active condensers}

Regions where low technology systems are more appropriate tend to use passive radiative condensers or solarenergy based regenerative desiccant condensers. However, active condensers may prove useful in regions and situations where conventional sources of water are not available and a higher yield is required, such as for providing potable water for isolated communities in arid regions or insular areas. The usefulness of active condensers depends on their design and intended application. For instance, active condensers using cooling condensation technology generally provide the benefit of being more portable than regenerative desiccation systems. Traditionally, desiccants allowed for function of condensers at lower dew point temperatures because there was no concern that the condenser coils would freeze. However, insulation and programmable chipsets have allowed for the design of condensers that can remain functional at lower temperatures as well as perform within certain temperature ranges, so as to be more efficient depending on the local climate. The trend in regenerative desiccants has been to couple them with heat exchangers to improve their regeneration capabilities and enhance the yield.

Milani et al. (2011) estimated that $95 \%$ of the water costs of such technology can be attributed to energy consumption rather than the capital costs of the active condenser technology. However, this is difficult to quantify, as energy consumption varies with the design of the condenser. For example, a life-cycle assessment of active condensers in comparison to refrigerators has shown that active condensers powered by conventional, non-renewable energy sources consume more electricity for operation than refrigerators. In addition, active condensers powered by conventional sources of energy require 4-8 L of virtual water to produce one liter of potable water, excluding condensed vapor, based on the source of power $(99 \%$ of this water is a consequence of coal washing and power station cooling operations used to provide electrical power) (Peters et al. 2013). The high energy consumption also raises environmental concerns related to emission of greenhouse gases. For example, active condensers produce 
nearly three orders of magnitude more greenhouse gases than seawater desalination plants (Peters et al. 2013). It should be emphasized that these analyses were based on active condensers that were powered by conventional electricity sources.

Given that $99 \%$ of the water use and greenhouse gas emissions of active condensers are associated with the power supply, the obvious way to improve these generators is to utilize renewable sources of energy, such as wind or solar. With such a power supply, the active condensers would significantly outperform sea water desalination plants on greenhouse emissions. Overall, it is likely to be environmentally safer and more cost-effective to utilize active condensers powered by renewable energy sources. Although including a solar power unit to provide the power required for active condensers will increase the capital cost, the operation costs as well as the cost per liter will be reduced significantly.

Khalil et al. (2014) suggested an independent dew water irrigation system (IDWIS), which consists of four main components: a solar power unit, active condenser(s), water reservoir, and a drip irrigation system. The design of the IDWIS consists of four steps. First, the irrigation demand is computed based on the area cultivated and the crop type. Second, the reservoir is designed to store the amount of water required for the maximum irrigation event. Third, the number of condensers is identified based on the amount of water required for the maximum irrigation event and the productivity of a single condenser. Fourth, the solar power unit is designed based on the energy required for the number of condensers identified in the third step.

Other designs utilize seawater to enhance cooling and to reduce the energy demands of cooling condensation condensers. The seawater greenhouse prototype may be a useful tool to better understand the enhanced cooling by means of seawater (Wahlgren 2000). This prototype uses cool seawater that is pumped into a greenhouse and channeled between a condenser and evaporators to enhance the cool and humid conditions in the greenhouse that are required for plant growth, as well as to produce fresh water condensate. There are certain constraints to this technology, including that the location must be coastal, capital costs are high, and water is relatively expensive at the rate of \$0.005-0.012/L (Wahlgren 2000). However, these costs can be attenuated by selling the products grown inside the greenhouse for a profit.

Overall, although water production from active condensers remains relatively costly at present, active condensers are still beneficial in appropriate situations and there are several promising developments in their design that overcome key shortcomings of earlier models. However, while technological development has been extensive, little research has been conducted into design optimization for particular conditions to maximize yield. The reliability of coupled renewable energy sources and other alternative cooling mechanisms has also not been evaluated. These issues must be explored further for active dew condensers to be a reliable source of water in regions where supply and quality of water from other conventional sources are poor.

\section{Conclusion}

Dew forms on surfaces when the surface temperature is lower than the dew point temperature. For water condensation to occur; there are several environmental conditions that must be met. A high relative humidity, high sky visibility to infrared radiation, and low wind speed are required, which therefore means that the volumes of dew formed are highly variable. Radiative dew condensers rely solely on the physical processes that induce dew formation naturally. To maximize water condensation without any external source of energy, radiative condensers can be optimized in terms of their shape, size, material (hydrophilic properties, mass, infrared emittance), and position (inclination, shading, sky exposure, and orientation). Such condensers are an interesting source of alternative water because they do not require any additional energy input, and the highest yields collected - up to $0.6 \mathrm{~mm} / \mathrm{day} /$ $\mathrm{m}^{2}$-are predominantly in regions of water scarcity (arid and semi-arid regions). Despite optimization, radiative condensers are still highly dependent on the weather conditions, making this a relatively unreliable source of water. In addition, yields will remain low, since the scaling up the condenser size from $1 \mathrm{~m}^{2}$ has been found to decrease efficiency.

Compared to radiative condensers, active condensers are more efficient, with daily yields proven to be considerably higher (e.g., 15-50 L/day for a small portable drinking water unit). Active condenser technology takes two main forms: regenerative desiccant materials and cooling condensation systems. The first of the two uses hygroscopic substances that can attract and hold water molecules, from which water is subsequently extracted using a specific stimulus such as solar regeneration, heat exchange, or air paths and chambers. With this type of system, higher volumes of water can be extracted from the air than can be extracted using radiative condensers. Cooling condensation systems contain the components of a refrigeration system to provide a cooled surface for condensation to occur. Similar to radiative condensers, they are optimized to lower the temperature of a specific surface to below the dew point temperature. However, the cooling condensation systems are able to create a larger temperature difference between the air temperature and the surface temperature than radiative condensers. 
Thus, active condensers hold promise as an alternative or supplemental source of water in regions where conventional water supplies are limited or unavailable, due to the higher yields produced than those of radiative condensers. Nevertheless, they are more expensive and tend to have high energy demands. Several recent innovations offer solutions for reducing the energy requirements, such as coupling condensers with ground heat exchangers or vehicles, and using seawater for cooling. In addition, the majority of activity in relation to active condensers has been in technological innovation, with research into their efficiency being relatively limited compared to radiative condensers. If active condensers are to achieve their potential, research is needed to evaluate the existing technologies in terms of yield under different conditions, to optimize their design and reduce their energy requirements.

Acknowledgments Financial support provided by Sustainable Project Funds of McGill University, as well as an NSERC Discovery Grant held by Jan Adamowski, is acknowledged.

\section{References}

Ackerman E (1968) Production of water from the atmosphere. US Patent No. 3400515, US Patent and Trademark Office, Washington

Agam N, Berliner PR (2006) Dew formation and water vapor adsorption in semi-arid environments-a review. J Arid Environ 65:572-590

Alnaser WE, Barakat A (2000) Use of condensed water vapour from the atmosphere for irrigation in Bahrain. Appl Energy 65:3-18

Altenkrich E (1938) Method of gaining water from the atmosphere. US Patent No. 2138689, US Patent and Trademark Office, Washington

Beysens D (1995) The formation of dew. Atmos Res 39:215-237

Beysens D, Milimouk I, Nikolayev V, Muselli M, Marcillat J (2003) Using radiative cooling to condense atmospheric vapour: a study to improve water yield. J Hydrol 276:1-11

Beysens D, Ohayon C, Muselli M, Clus O (2006) Chemical and biological characteristics of dew and rain water in an urban coastal area (Bordeaux, France). Atmos Environ 40:3710-3723

Beysens D, Clus O, Mileta M, Muselli M, Milimouk I, Nikolayev VS (2007) Collecting dew as a water source on small islands: the Dew Equipment for Water Project in Biseva (Croatia). Energy 32:1032-1037

Beysens D, Broggini F, Milimouk-Melnytchouk I, Ouazzani J, and Tixier N (2012) Dew architectures: dew announces the good weather. materiality in its contemporary forms: architectural perception, fabrication and conception, pp 283-292

Biancardi RP (1982) Apparatus and method for automatically watering vegetation. US Patent No. 4315599, US Patent and Trademark Office, Washington

Bulang W (1980) Process and plant for recovering water from moist gas. US Patent No. 4185969, US Patent and Trademark Office, Washington

Bundschuh J, Hoinkins J (2012) Renewable energy applications for freshwater production. CRC Press, Florida

Call CJ, Beckius RC, Merrill EL, Hong SH, Powell M (2009) Method and apparatus for generating water using an energy conversion device. US Patent No. 7601206, US Patent and Trademark Office, Washington

Clus O, Ortega P, Muselli M, Milimouk I, Beysens D (2008) Study of dew water collection in humid tropical islands. J Hydrol 361:159-171

Clus O, Ouazzani J, Muselli M, Nikolayev VS, Sharan G, Beysens D (2009) Comparison of various radiation-cooled dew condensers using computational fluid dynamics. Desalination 249:707-7012

Coanda H, Coanda MH (1956) Device for obtaining fresh drinkable water. US Patent No. 2761292, US Patent and Trademark Office, Washington

Courneya CG (1982) Apparatus for extracting potable water. US Patent No. 4351651, US Patent and Trademark Office, Washington

Craven JP (2008) Fresh water extraction device. US Patent 7328584 , US Patent and Trademark Office, Washington

Dagan A (2003) Apparatus for extracting potable water from the environment air. US Patent 6644060, US Patent and Trademark Office, Washington

Dunkak EB (1949) Solar activated dehumidifier. US Patent No. 2462952, US Patent and Trademark Office, Washington

Ellsworth J (2013) Composite desiccant and air-to-water system and method. US Patent No. 8506675, US Patent and Trademark Office, Washington

Engel DR, Clasby ME (2004) Apparatus and method for extracting potable water from atmosphere. US Patent 6755037, US Patent and Trademark Office, Washington

Faqih AAM (2004) Apparatus for the production of freshwater from extremely hot and humid air. US Patent 6684648, US Patent and Trademark Office, Washington

Faqih AAM (2005) Production of potable water and freshwater needs for human, animal and plants from hot and humid air. US Patent 6868690, US Patent and Trademark Office, Washington

Foss FD (1973) Humidifier-dehumidifier device. US Patent No. 3740959, US Patent and Trademark Office, Washington

Gandhidasan P, Abualhamayel HI (2005) Modeling and testing of a dew collection system. Desalination 180:47-51

Gindel I (1965) Irrigation of plants with atmospheric water within the desert. Nature 207:1173-1175

Gläser HJ, Ulrich S (2013) Condensation on the outdoor surface of window glazing - calculation methods, key parameters and prevention with low emissivity coatings. Thin Solid Films 532:127-131

Graham CD, Dybvig ES (1946) Refrigerating apparatus. US Patent 2401560, US Patent and Trademark Office, Washington

Groth W, Hussmann P (1979) Process and system for recovering water from the atmosphere. US Patent No. 4146372, US Patent and Trademark Office, Washington

Hamed AM, Kabeel AE, Zeidan EB, Aly AA (2010) A technical review on the extraction of water from atmospheric air in arid zones. JP J Heat Mass Transfer 4(3):213-228

Hamed AM, Aly AA, Zeidan EB (2011) Application of solar energy for recovery of water from atmospheric air in climatic zones of Saudi Arabia. Nat Resour 2(1):8-17

Hussmann P (1982a) Method and apparatus for abstracting water from air. US Patent No. 4342569, US Patent and Trademark Office, Washington

Hussmann P (1982b) Method and apparatus for recovery of water from the atmosphere. US Patent No. 4345917, US Patent and Trademark Office, Washington

Ito T, H Matsuoka, Azuma K, Y Hirayama, N Takahashi (1981) Water producing apparatus. US Patent No. 4304577, US Patent and Trademark Office, Washington

Jacobs AFG, Heusinkveld BG, Lucassen DC (1998) Temperature variation in a class A evaporation pan. J Hydrol 206:75-83 
Jacobs AFG, Heusinkveld BG, Berkowicz SM (2008) Passive dew collection in a grassland area, The Netherlands. Atmos Res 87:377-385

Kabeel AE (2007) Water production from air using multi-shelves solar glass pyramid system. Renew Energy 32(1):157-172

Khalil B, Adamowski J, Rojas M, Reilly K (2014) Towards an independent dew water irrigation system for arid or insular areas. Proceedings of the ASABE international annual meeting, Montreal

Khalil B, Adamowski J, Ezzeldine M (2015) Dew water collection as non-conventional source of water. Proceedings of the 22nd Canadian hydrotechnical conference, Montreal, 29 Apr-2 May 2015

Kidron GJ (2000) Analysis of dew precipitation in three habitats within a small arid drainage basin, Negev Highlands, Israel. Atmos Res 55:257-270

Kidron GJ (2010) The effect of substrate properties, size, position, sheltering and shading on dew: an experimental approach in the Negev Desert. Atmos Res 98:378-386

Klemic J (2005) Atmospheric water absorption and retrieve device. US Patent No. 6869464, US Patent and Trademark Office, Washington

Krumsvik PK (1998) Method and device for recovering water from a humid atmosphere. US Patent No. 5846296, US Patent and Trademark Office, Washington

LeBleu TL (1997) Portable, Potable water recovery and dispensing apparatus. US Patent 5669221, US Patent and Trademark Office, Washington

LeBleu TL (1998) Portable/potable water recovery and dispensing apparatus. US Patent 5845504, US Patent and Trademark Office, Washington

Lekouch I, Lekouch K, Muselli M, Mongruel A, Kabbachi B (2012) Rooftop dew, fog and rain collection in southwest Morocco and predictive dew modeling using neural networks. J Hydrol 448-449:60-72

Lloyd DJ, Baier SE (2002) Water generating machine. US Patent 6490879, US Patent and Trademark Office, Washington

Maestre-Valero JF, Martinez-Alvarez V, Baille V, Martin-Gorriz B, Gallego-Elvira B (2011) Comparative analysis of two polyethylene foil materials for dew harvesting in a semi-arid climate. J Hydrol 410:84-91

Maestre-Valero JF, Ragab R, Martinez-Alvarez V, Bailie A (2012) Estimation of dew yield from radiative condensers by means of an energy balance model. J Hydrol 460:103-109

McCabe WI, Smith JC, Hariott P (1993) Unit operation of chemical engineering, 5th edn. McGraw Hill Chemical Engineering Series

Michel H, Bulang W (1981) Method and apparatus for the recovery of water from the atmospheric air. US Patent No. 4285702, US Patent and Trademark Office, Washington

Milani D, Abbas A, Vassallo A, Chiesa M, Al Bakri D (2011) Evaluation of using thermoelectric coolers in a dehumidification system to generate freshwater from ambient air. Chemical Eng Sci 66:2491-2501

Monteith JL, Unsworth MH (1990) Principles of environmental physics, 2nd edn. Routledge Chapman \& Hall Inc., New York
Muñoz-García MA, Moreda GP, Raga-Arroyo MP, Marín-González O (2013) Water harvesting for young trees using Peltier modules powered by photovoltaic solar energy. Comput Electron Agric 93:60-67

Muselli M, Beyesens D, Milimouk I (2006) A comparative study of two large radiative dew water condensers. J Arid Environ 64:54-76

Muselli M, Beysens D, Mileta M, Milimouk I (2009) Dew and rain water collection in the Dalmatian Coast, Croatia. Atmos Res 92:455-463

Nikolayev VS, Beysens D, Gioda A, Milimouk I, Katiushin E, Morel JP (1996) Water recovery from dew. J Hydrol 182:19-35

O'Hare LR (1984) Ground moisture transfer system. US Patent No. 4459177, US Patent and Trademark Office, Washington

Ockert CE (1978) Device for extracting energy, fresh water and pollution from moist air. US Patent No. 4080186, US Patent and Trademark Office, Washington

Peters GM, Blackburn NJ, Armedion M (2013) Environmental assessment of air to water machines - triangulation to manage scope uncertainty. Int J Life Cycle Assess 18:1149-1157

Reidy JJ (1992a) Potable air-water generator. US Patent 5106512, US Patent and Trademark Office, Washington

Reidy JJ (1992b) Potable water generator. US Patent 5149446, US Patent and Trademark Office, Washington

Reidy JJ (1993) Potable air-water generator. US Patent 5203989, US Patent and Trademark Office, Washington

Rodriguez F, Khanji NK (2012) Low power atmospheric water generator. US Patent No. 8118912, US Patent and Trademark Office, Washington

Rogers W, Midgett P (1980) Underground heating and cooling system. US Patent No. 4234037, US Patent and Trademark Office, Washington

Shank DB (2006) Dew point temperature prediction using artificial neural networks. MS thesis, Department of Biological and Agricultural Engineering, University of Georgia, Athens

Sharan G, Beysens D, Milimouk-Melnytchouk I (2007) A study of dew water yields on galvanized iron roofs in Kothara (NorthWest India). J Arid Environ 69:259-269

Smith RH (1984) Apparatus and method for recovering atmospheric moisture. US Patent No. 4433552, US Patent and Trademark Office, Washington

Tircot M (1985) Apparatus for continuously metering vapours contained in the atmosphere. US Patent No. 4506510, US Patent and Trademark Office, Washington

Tongue S (2007) Water-from-air system using desiccant wheel and exhaust. US Patent 7251945, US Patent and Trademark Office, Washington

Wahlgren RV (2000) Atmospheric water vapour processor designs for potable water production: a review. Water Resour 35(1):1-22

Xu Y, Yan B, Zhu H, Guan J (2013) Dew condensation monitoring in a wetland ecosystem in the sanjiang plain. Fresenius Environ Bull 22(5):1351-1356

Zakryk JM (2000) Water collection and dispensing. US Patent 6029461, US Patent and Trademark Office, Washington 